\title{
Ring switching tricomponent synthesis of pyrano[2,3-b]pyridine multifunctional derivatives
}

\author{
Boris V. Paponov, ${ }^{* a}$ Danil A. Rakityansky, ${ }^{a}$ Marina S. Samokhvalova, ${ }^{a}$ Gleb L. Denisov, ${ }^{b}$ \\ Andrey Yu. Potapov ${ }^{c}$ and Khidmet S. Shikhaliev \\ ${ }^{a}$ Belgorod National Research University, 308015 Belgorod, Russian Federation. \\ E-mail: paponov@bsu.edu.ru \\ ${ }^{b}$ A. N. Nesmeyanov Institute of Organoelement Compounds, Russian Academy of Sciences, \\ 119991 Moscow, Russian Federation \\ ${ }^{c}$ Voronezh State University, 394006 Voronezh, Russian Federation
}

DOI: 10.1016/j.mencom.2021.05.041

\begin{abstract}
New 3-acylamino-7-hydroxy-5-methyl-2-oxo-2H-pyrano[2,3-b]pyridine-6-carbonitriles were synthesized via a tricomponent condensation of 3-cyano-4-methyl-1,2,5,6-tetrahydropyridine-2,6-dione, triethyl orthoformate and $N$-acylglycines under the Erlenmeyer-Plöchl reaction conditions. According to $\mathrm{X}$-ray data, in the solid phase they exist as hydroxypyridine tautomer form.
\end{abstract}

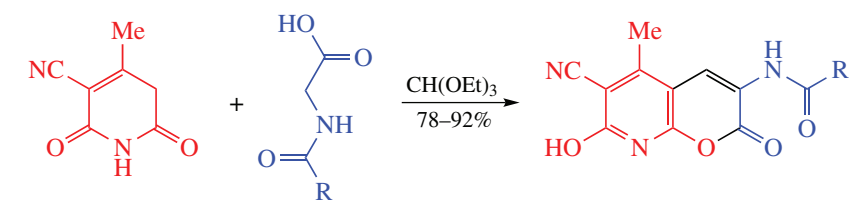

Keywords: 2H-pyrano[2,3-b]pyridinones, 1,2,5,6-tetrahydropyridine-2,6-dione, hippuric acid, triethyl orthoformate, tricomponent condensation, ring switching, Erlenmeyer-Plöchl reaction.

The 8-aza- and 7-hydroxycoumarine (umbelliferone) derivatives are regarded effective 'blue fluorescence' agents. Even more interesting and promising are coumarin derivatives simultaneously containing both 8-aza- and 7-hydroxy-units in one molecule. ${ }^{1-3}$ Previously, the classical syntheses of $\mathrm{N}$-aroyl-3-amino- $2 \mathrm{H}$ chromen-2-ones and their pyrano-fused hetarene analogues involving sequential condensations of phenols, naphthols or hydroxy-substituted heterocycles with dimethylformamide dimethyl acetal and hippuric acid esters were performed; ${ }^{4-7}$ the final products did not depend on the sequence of condensations between the starting reactants. The synthesis of such heterocyclic systems in three-component condensation reactions has been described for phenols, naphthols, or hydroxy-substituted heterocycles but not for azaheterocycles containing amido- or imido-moieties. ${ }^{8-11}$

Herein, we have proposed a convenient synthesis of substituted 8-aza-7-hydroxycoumarins based on the abovementioned general synthetic approach. Continuing the study of the Erlenmeyer-Pöchl reaction $^{12}$ and multicomponent condensations with 3-cyano-4methylpyrimidine-2,6-dione and orthoformates, ${ }^{13}$ we have performed the three-component assemling of 3-cyano-4methylpyridine-2,6-dione 1 with triethyl orthoformate and a number of $N$-acylglycines $\mathbf{2 a - g}$ under the Erlenmeyer-Plöchl conditions (Scheme 1). When the starting reagents were heated in acetic anhydride, brightly colored, red-orange betain-like intermediates A precipitated. Upon further heating, the colour of the precipitate quickly disappeared, and 3-acylamino-7-hydroxy-5-methyl-2-oxo$2 H$-pyrano[2,3-b]pyridine-6-carbonitriles $\mathbf{3 a - g}$ were formed. ${ }^{\dagger}$

†eneral procedure. A mixture of 3-cyano-4-methyl-1,2,5,6-tetrahydropyridine-2,6-dione 1 ( $300 \mathrm{mg}, 2 \mathrm{mmol}$ ), triethyl orthoformate ( $385 \mathrm{mg}$, $2.6 \mathrm{mmol})$ and hippuric acid $2 \mathrm{a}(360 \mathrm{mg}, 2 \mathrm{mmol})$ was heated in $\mathrm{Ac}_{2} \mathrm{O}$ $(1.5 \mathrm{ml})$ for $1 \mathrm{~h}$. The red-coloured intermediate appears and quickly turns into a white precipitate. The final product was filtered off and washed
Unfortunately, confirmation of the intermediate structure A using NMR spectroscopy turned out unsuccessful. The red intermediate underwent rapid recyclization into white product 3 when dissolved in DMSO, DMF or pyridine, even on cooling. Testing other solvents looked not valuable for NMR studies.

Attempts to carry out the reaction in acetic acid or in DMF did not bring about any products, and only the starting reactants were recovered. An attempt to introduce $N$-phthaloylglycine instead of hippuric acid was also unsuccessful. This fact may be an indirect evidence in favor of the intermediate structure $\mathbf{A}$ formed at the first stage of the Erlenmeyer-Pöhl process. ${ }^{14}$

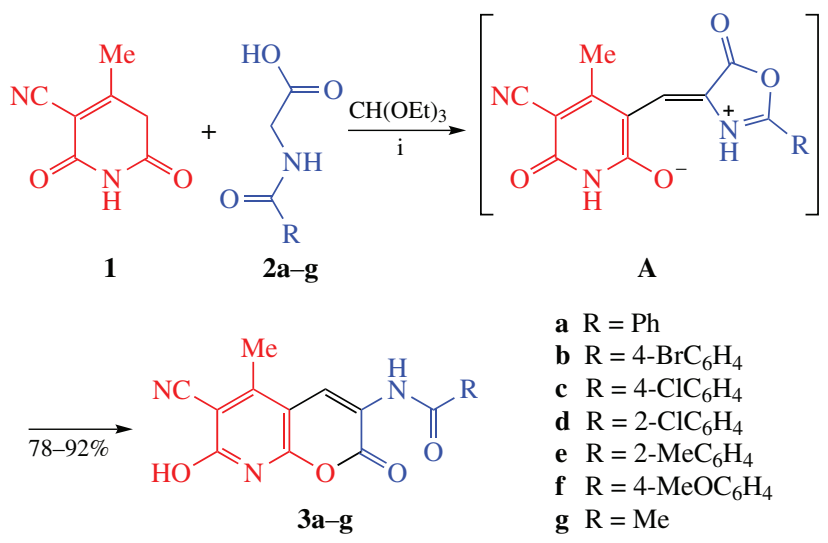

Scheme 1 Reagents and conditions: i, $\mathrm{Ac}_{2} \mathrm{O}, 120^{\circ} \mathrm{C}, 1 \mathrm{~h}$.

with ethyl alcohol to give 3-benzoylamino-7-hydroxy-5-methyl-2-oxo$2 H$-pyrano[2,3- $b$ ]pyridine-6-carbonitrile 3a. Yield $86 \%$ (550 mg). White solid, $\mathrm{mp}>300^{\circ} \mathrm{C}$.

Compounds $\mathbf{3 b}-\mathbf{g}$ were prepared similarly. For their characteristics, see Online Supplementary Materials. 
Subsequently, intermediate A underwent a ring switching transformation ${ }^{15}$ similar to the Zimmer's recycling ${ }^{16,17}$ to afford final products $\mathbf{3 a}-\mathbf{g}$.

The ${ }^{1} \mathrm{H}$ NMR spectra of compounds $\mathbf{3}$ showed a singlet for the protons of the methyl group of the pyridinedione ring, signals for the aromatic protons (compounds 3a-f) or the acetyl protons (compound 3g). Two singlets and one broad singlet with an integral intensity of one proton each also appear for compounds 3a-g in the low field area. Although the ${ }^{1} \mathrm{H}$ NMR spectra (DMSO- $d_{6}$ ) contained only one set of signals, it was difficult to make a right choice between 2-hydroxypyridine $\mathbf{3 a}-\mathbf{g}$ and pyridin-2-ones $\mathbf{3}$ 'a-g tautomeric forms.<smiles>[R]C(=O)Nc1cc2c(C)c(C#N)c(O)nc2oc1=O</smiles><smiles>[R]C(=O)Nc1cc2c(C)c(C#N)c(=O)[nH]c2oc1=O</smiles>

The product structure was ultimately elucidated from X-ray diffraction study ${ }^{\ddagger}$ for compound 3 f. Single crystals suitable for such purpose were isolated with DMF as a lattice solvent in a ratio of $1: 1$ (Figure 1), assisted by a rather strong hydrogen bond $\mathrm{O}-\mathrm{H} \cdots \mathrm{O}\left[\mathrm{O} \cdots \mathrm{O} 2.528(2) \AA\right.$, OHO $\left.167.42(12)^{\circ}\right]$ with the hydroxy group of the product 3 f being a 7-hydroxy tautomer. The molecule is nearly planar with an angle between mean-square planes of the pyranopyridine and phenyl moieties joined by an amide group equal to $7.19(6)^{\circ}$.

As a result, two types of intermolecular stacking interactions are produced, one between two symmetry-equivalent pyridine rings and one between the pyridine ring and the phenyl group; the corresponding centroid-centroid distances, angles between the planes and their shifts are 3.7685(16) and 3.7440(13) A,

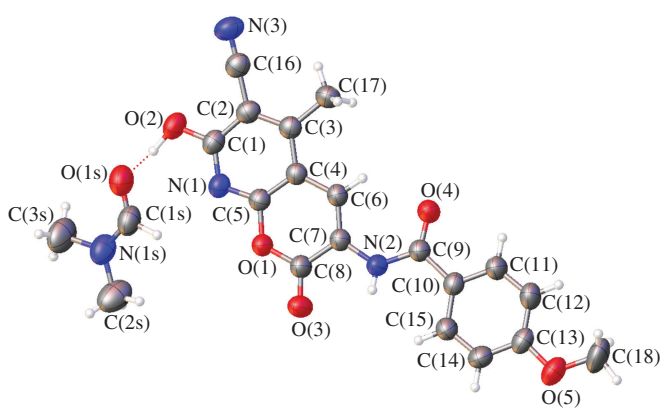

Figure 1 General view of compound $\mathbf{3 f}$ in representation of non-hydrogen atoms via thermal ellipsoids with a probability level of $50 \%$.

\# Crystal data for 3f. $\mathrm{C}_{21} \mathrm{H}_{20} \mathrm{~N}_{4} \mathrm{O}_{6}(M=424.41)$, triclinic, space group $P \overline{1}$, at $296 \mathrm{~K}: a=8.5205(4), b=10.9920(5)$ and $c=11.7307(5) \AA$, $\alpha=104.150(2), \beta=98.285(3)$ and $\gamma=99.863(3)^{\circ}, V=1029.51(8) \AA^{3}$, $Z=2, \quad d_{\text {calc }}=1.369 \mathrm{~g} \mathrm{~cm}^{-3}, \quad \mu(\mathrm{MoK} \alpha)=1.02 \mathrm{~cm}^{-1}, \quad F(000)=444$. Intensities of 17013 reflections were measured with a Bruker D8 Quest CCD diffractometer $\left[\lambda(\mathrm{MoK} \alpha)=0.71073 \AA\right.$, $\omega$-scans, $\left.2 \theta<52^{\circ}\right]$, and 4059 independent reflections $\left(R_{\text {int }}=0.0572\right)$ were used in the further refinement. Using Olex $2,{ }^{18}$ the structure was solved with the ShelXT ${ }^{19}$ structure solution program using Intrinsic Phasing and refined with the $\mathrm{XL}^{20}$ refinement package using Least Squares minimization. Hydrogen atoms of $\mathrm{NH}$ and $\mathrm{OH}$ groups were located from difference Fourier synthesis, positions of others were calculated, and they all were refined in the isotropic approximation using the riding model. The refinement converged to $w R_{2}=0.1553$ and $\mathrm{GOF}=1.009$ for all the independent reflections $\left[R_{1}=0.0501\right.$ was calculated against $F$ for 2582 observed reflections with $I>2 \sigma(I)]$.

CCDC 2054855 contains the supplementary crystallographic data for this paper. These data can be obtained free of charge from The Cambridge Crystallographic Data Centre via http://www.ccdc.cam.ac.uk.
$0.0(2)$ and $7.19(6)^{\circ}, 1.660(2)$ and $1.407(2) \AA$, respectively. The amino group is involved in a rather weak $\mathrm{N}-\mathrm{H} \cdots \mathrm{O}$ bond $[\mathrm{N} \cdots \mathrm{O}$ $3.312(2) \AA$, NHO $134.58(11)^{\circ}$ ] with the oxo group at the pyranopyridine moiety, thus producing a centrosymmetric dimer from the neighbouring molecules of $\mathbf{3 f}$. Other weak interactions, such as $\mathrm{C}-\mathrm{H} \cdots \mathrm{O}, \mathrm{C}-\mathrm{H} \cdots \mathrm{N}$ and $\mathrm{C}-\mathrm{H} \cdots$ pi, complete the formation of the $3 \mathrm{D}$ framework.

In summary, the one-pot three-component procedure for the synthesis of new 3-acylamino-7-hydroxy-5-methyl-2-oxo- $2 \mathrm{H}$ pyrano[2,3- $b$ ]pyridine-6-carbonitriles as new 8-aza-7-hydroxycoumanine derivatives was accomplished with high yields under the Erlenmeyer-Plöchl reaction conditions. The further study of this procedure for similar condensation with other ortho esters, methylene active compounds, and hippuric acids is in progress.

X-ray diffraction data were collected with the financial support from Ministry of Science and Higher Education of the Russian Federation using the equipment of Center for Molecular Composition Studies of INEOS RAS.

Online Supplementary Materials

Supplementary data associated with this article can be found in the online version at doi: 10.1016/j.mencom.2021.05.041.

\section{References}

1 H. Takano, T. Narumi, N. Ohashi, A. Suzuki, T. Furuta, W. Nomura and H. Tamamura, Tetrahedron, 2014, 70, 4400.

2 H. Takano, T. Narumi, W. Nomura and H. Tamamura, Org. Lett., $2015, \mathbf{1 7}, 5372$

3 H. Takano, T. Narumi, W. Nomura and H. Tamamura, J. Org. Chem., 2017, 82, 2739 .

4 B. Stanovnik and J. Svete, Chem. Rev., 2004, 104, 2433

5 J. Svete, Z. Čadež, B. Stanovnik and M. Tišler, Synthesis, 1990, 70

6 R. Toplak, J. Svete, B. Stanovnik and S. G. Grdadolnik, J. Heterocycl. Chem., 1999, 36, 225.

7 L. Kralj, A. Hvala, J. Svete, L. Golič and B. Stanovnik, J. Heterocycl. Chem., 1997, 34, 247.

8 V. Kepe, M. Kočevar and S. Polanc, Heterocycles, 1995, 41, 1299.

9 V. Kepe, M. Kočevar and S. Polanc, J. Heterocycl. Chem., 1996, 33, 1707

10 V. Kepe, S. Polanc and M. Kočevar, Heterocycles, 1998, 48, 671.

11 F. Požgan, K. Kranjc, V. Kepe, S. Polanc and M. Kočevar, ARKIVOC, 2007, (viii), 97.

12 B. V. Paponov, S. V. Lvov, E. V. Ichetovkina, I. A. Panasenko and S. G. Stepanian, Mendeleev Commun., 2012, 22, 273.

13 J. S. Oshega, B. V. Paponov, I. V. Omelchenko and O. V. Shishkin, Mendeleev Commun., 2015, 25, 133.

14 E. Erlenmeyer, Liebigs Ann. Chem., 1893, 277, 275.

15 A. Dinsmore, P. M. Doyle and D. W. Young, Tetrahedron Lett., 1995, 36, 7503.

16 H. Wamhoff and F. Korte, Synthesis, 1972, 151.

17 H. Zimmer and J. Rothe, J. Org. Chem., 1959, 24, 28.

18 O. V. Dolomanov, L. J. Bourhis, R. J. Gildea, J. A. K. Howard and H. Puschmann, J. Appl. Crystallogr., 2009, 42, 339.

19 G. M. Sheldrick, Acta Crystallogr., 2015, A71, 3.

20 G. M. Sheldrick, Acta Crystallogr., 2008, A64, 112. 